\title{
Effects of a Mindful Parenting Workshop for Parents of Adolescents and Young Adults Following Social Unrest in Hong Kong
}

\author{
Herman Hay Ming Lo ${ }^{1}$. Elsa Nga Sze Lau ${ }^{2}$. Cherry Hiu Lin Tam ${ }^{3}$. So Wa Ngai ${ }^{1}$. Sunny Ho Wan Chan ${ }^{1}$. \\ Bobby Fook Hin Leung ${ }^{1}$. Emma Ting Wong ${ }^{4} \cdot$ Elisabeth Wai Yin Wong ${ }^{5}$. Gloria Oi Chi Wong ${ }^{6} \cdot$ Wan Chi Cho ${ }^{7}$. \\ Alfert Wai Kiu Tsang ${ }^{5,8} \cdot$ Nirbhay N. Singh ${ }^{9}$
}

Accepted: 9 November 2021 / Published online: 2 December 2021

(c) The Author(s), under exclusive licence to Springer Science+Business Media, LLC, part of Springer Nature 2021, corrected publication 2021

\begin{abstract}
Objectives The social unrest that began in Hong Kong in 2019 became a threat to public mental health, such as for depression and post-traumatic stress disorders. A supportive family environment is the most effective protective factor for mental health problems for young people who are exposed to conflict and violence. This study investigated the outcomes of a brief mindful parenting workshop on parent mental health and family functioning.

Methods Using a randomized controlled trial design, 54 parents of adolescents and young adults were randomized into intervention group and waitlist control group. Depression, anxiety, post-traumatic stress symptoms, negative emotions, family functioning, and family conflicts were measured at baseline (pretest), following training, and at 3-month follow-up. Results We found a significant improvement in family functioning among parents in the intervention group when compared to those parents in the control group $(F[1,51]=4.41, p=.04)$. When we further controlled the child-initiated physical conflict as covariate, a significant reduction of self-rated levels of depressive symptoms was found in the parents from the intervention group when compared to the parents in the control group $(F[1,49]=5.14, p=.03)$.

Conclusions We found preliminary evidence that a brief mindful parenting workshop can strengthen parent and family mental health at times of social unrest.

Trial Registration ClinicalTrials.gov (NCT04427683).
\end{abstract}

Keywords Mindfulness-based intervention $\cdot$ Mindful parenting $\cdot$ Parents $\cdot$ Adolescents $\cdot$ Social unrest

Herman Hay Ming Lo

herman.lo@polyu.edu.hk

Hong Kong Polytechnic University, Kowloon, Hong Kong

2 The Education University of Hong Kong, Tai Po, New Territories, Hong Kong

3 City University of Hong Kong, Kowloon Tong, Hong Kong

4 Private Practice, Kowloon, Hong Kong

5 Hong Kong College of Psychiatrists, Aberdeen, Hong Kong

6 Lingnan University, Tuen Mun, Hong Kong

7 Caritas Medical Centre, The Hospital Authority, Sham Shui Po, Hong Kong

8 University of Hong Kong, Pok Fu Lam, Hong Kong

9 Medical College of Georgia, Augusta University, Augusta, GA, USA
As Hong Kong experienced a period of social unrest beginning in June 2019, a population-based study of adults aged 18 or older reported a prevalence of major depression of $11.2 \%$, compared with $1.9 \%$ during 2009 , and that of suspected PTSD was estimated to be $12.8 \%$ (Ni et al., 2020). A few studies have investigated how social unrest has affected family relationships since the 2014 umbrella movement. In a qualitative study, Ho et al. (2018) found intra-familial conflict and different levels of renegotiation in family relationships of active participants and bystanders in the political movement. In a study of young adults and their family members, Chan et al. (2018) found that lower relationship quality and lower congruence in their political attitudes predicted more serious subsequent family conflicts, suggesting a close relationship between political and family life. Both studies suggested that some families may have stronger resilience while others experience serious and persistent conflicts, which may require professional attention. 
Studies have shown that social unrest and exposure to community violence have a strong detrimental impact on adolescent mental health (Herd \& Kim-Spoon, 2021; Townsend et al., 2020; Vorhies et al., 2011). Mental health issues, particularly post-traumatic stress, are common during social unrest but they can be moderated by positive parental mental health and positive parenting (Dubow et al., 2012). Post-traumatic stress is caused by actual or threatened death or serious injury, direct exposure to violence, witnessing a significant person's exposure to violence or an accident, or indirect exposure through hearing aversive details of the event (American Psychiatric Association, 2013). Core symptoms of post-traumatic stress include re-experiencing the trauma, avoidance, and a persistent sense of threat. Prolonged symptoms may lead to issues with affective dysregulation, negative self-concept, and relationship disturbances (Cloitre et al., 2018). About 6-20\% of individuals develop post-traumatic stress disorder after a potentially traumatic event (Kahana et al., 2006). Other mental health issues including depression, anxiety, paranoid ideation, and aggression have been found in adolescents with extensive exposure to community violence (Al-Krenawi \& Graham, 2012).

A supportive family environment is the most consistent mediator of this impact (Cummings et al., 2016). For example, in Northern Ireland, where a significant proportion of adolescents have been exposed to community conflict, emotional insecurity and family cohesion predicted subsequent adolescent delinquency and aggression (Cummings et al., 2016; Taylor et al., 2016). Adolescents living with parents who have different life values and exert high psychological control may lack a buffer against the threat of mental health problems during social unrest. Thus, this age group is at the highest risk of developing chronic mental health issues after exposure to traumatic life experiences (de Jong et al., 2015).

Social identity theory suggests that our social world can be categorized into ingroups and outgroups and that this influences our perceptions and behaviors in different contexts. While earlier studies on intergroup dynamics focused on relationships between strangers, more recent research on intergroup dynamics and conflicts extend to more personal relationships, including families (Soliz \& Rittenour, 2012). The parent-adolescent relationship is often fueled by age group distinctions, as many parents experience challenges and difficulties where peer relationships of their children overpower family influences (Soliz \& Rittenour, 2012). Such age differences can extend to the influence of birth cohort, and communication among members of different generations or birth cohorts can be problematic when the social status and economic resources of one cohort have conflicts with those of another (Hummert, 2012). In the context of social unrest, intensive conflicts among generations within families that are characterized as major differences in essential goals, needs, and values, and are perceived as irresolvable may lead to an enduring and destructive mutual violence over time (Halperin, 2015).

In the context of Hong Kong, greater dissatisfaction has been reported among younger than the older generation (Wong et al., 2020), and the trend is toward the younger generation's growing participation in the political movement for expressing their dissatisfaction with existing social and political structures (Lam-Knott, 2018). On the other hand, traditional Chinese parenting principles expect total obedience of children and a lack of personal space to express dissatisfaction that are still common in many Hong Kong families (Shek \& Sun, 2014). A reconsideration of the overemphasis on family harmony and strict parental control, and a search for parenting principles that balance younger family members' need for security and identity with continuing family bonding during this critical time is recommended.

Intervention targeted to resolve intractable conflicts involves successful emotion regulation that requires the motivation and skills in cognitive reappraisal and regulation of negative emotions (Gutentag et al., 2017). In a noncongruent emotional process, parents are more likely to regulate their emotions to balance the emotional responses of the adolescents. For example, Goldenberg et al. (2017) found that parents who placed their values on family unity were motivated to regulate and compensate in high-intensity negative responses that can promote relationship quality. However, parents need to adjust their perspective in managing their relationship with adolescent children and to learn emotion regulation strategies that can promote positive affective change and facilitate empathy and reconciliation in families and communities (Čehajić-Clancy et al., 2016).

Some intervention programs combine mindfulness skills with psychoeducation as a strategy for promoting security, connection, and emotion regulation (Chambers et al., 2009). Mindfulness is a process of regulating attention in order to bring a quality of non-elaborative awareness to current experience and a quality of relating to one's experience within an orientation of curiosity, experiential openness, and acceptance (Bishop et al., 2004). Mindfulness-based interventions have been widely adopted as a therapeutic approach for reducing emotional distress and promoting psychological well-being, including post-traumatic stress (Banks et al., 2015; Gu et al., 2015). Growing research suggests that strengthening mindfulness in parents results in enhanced compassion in children, and non-judgmental acceptance and greater emotional awareness in parents (Lo et al., 2018a, b).

Although there have been relatively more studies of mindful parenting interventions with parents of young children, some studies have reported that training in mindfulness can benefit parents of adolescents and their interaction. For example, Lippold et al. (2015) found that mindful parenting can improve mother-adolescent communication by reducing parental negative reactions to information, adolescent 
perceptions of over-control, and by improving the affective quality of the parent-adolescent relationship. In a study with parents of children 10-14 years of age, Coatsworth et al. (2015) integrated mindfulness with the Strengthening Families Program and compared the effects with the Strengthening Families Program alone in a randomized controlled trial. Results showed that both programs improved multiple dimensions of parenting, including interpersonal mindfulness in parenting, parent-youth relationship quality, youth behavior management, and parent well-being, with fathers showing more sustained effects with the mindfulnessenhanced program than with the Strengthening Families Program alone. In a study targeting highly stressed mothers of adolescents aged 12 to 17, Chaplin et al. (2021) reported significantly larger improvements in parenting stress relating to parent life restrictions, relationship with spouse, and emotional awareness in parenting when compared with those completing a parent education program without a mindfulness component. In addition, a recent systematic review and meta-analysis of 25 mindfulness-based parenting programs for parents of adolescents reported a small, post-intervention reduction in parenting stress and youth outcomes (Burgdorf et al., 2019).

Similar studies are unavailable in the context of social unrest, but a study from Israel showed that after being presented with anger-inducing information related to political conflict, 101 adult participants in a mindfulness workshop were more supportive of conciliatory policies, with the effects being mediated by a reduction in perceived threat and improvement in emotion regulation (Alkoby et al., 2017).

The aim of the present study was to evaluate the effects of a mindful parenting workshop for parents of adolescents and young adults after social unrest in Hong Kong. We undertook a mixed methods study to quantitatively evaluate the effects of the mindfulness-based support program on the parents' depressive and post-traumatic symptoms, perceived family functioning, and changes in family conflicts. We qualitatively explored their subjective experiences of the mindfulness-based parent support program and its perceived benefits.

\section{Methods}

\section{Participants}

Participants were recruited from the general public and school social workers from five major youth service NonGovernmental Organizations (NGOs) in Hong Kong. This is an indicated prevention program and the workshop is targeted for parents who are screened as having an increased vulnerability for mental disorders or severe family conflicts (Gordon, 1983). The inclusion criteria for this study were
(1) participants should be parents of adolescents or young adults aged 12 to 30, and (2) parents reported a score of Patient Health Questionnaire (PHQ-9) of 5 or above, representing a mild level of depression or above (Kroenke et al., 2001). We did not collect additional information in view of the concerns and sensitivity about data collection in relation to the social unrest in Hong Kong during the study period.

The workshop was promoted through NGO collaborators, the research team, university website, project Facebook page, and emails to all secondary schools in Hong Kong. Unfortunately, the recruitment was adversely affected by onset of the COVID-19 virus and some parents had concerns about health safety and limited access to the Internet. An initial total of 124 parents enrolled in the study. After screening, 37 had a PHQ-9 total score below 5 and did not meet the inclusion criteria. Another 14 withdrew due to their unavailability for the training, 9 indicated that they were not interested in the study, mostly due to the face-to-face delivery format, and 11 lost contacts. A research assistant was responsible for conducting the briefing and screening of the project applicants. After screening, a total of 53 eligible parents were randomized into the intervention and the waitlist control groups (see Fig. 1). A second research assistant was responsible for the randomization of the families. The participating parents were randomly listed from 1 to 90 . Those assigned even numbers were allocated to the intervention group and those with odd numbers were assigned to the waitlist control group. After the families were assigned to the two groups, the second research assistant contacted them by phone, to inform them of the results of randomization and to confirm that both the parents and the child would participate in the study. The second Research Assistant who interviewed the families was thus blind to the group assignment process.

\section{Procedures}

This was a randomized waitlist control trial, with the waitlist group offered the same intervention at the conclusion of mindful parenting workshop and data collection for the experimental group. The parents could attend one of five workshops that could be accessed via local transportation.

\section{Intervention}

The Restoration and Reconnection: Mindful Parenting Workshop was developed by the first author as a brief version of the Mindful Parenting course (Bögels \& Restifo, 2014), an evidence-based program for reducing the stress of parents of adolescents with externalizing behaviors. The protocol for the brief Mindful Parenting Workshop was tested in a feasibility study with parents of preschool children with developmental disabilities (Lo et al., 2017). The 
Fig. 1 Flow diagram of the process for randomized controlled trial

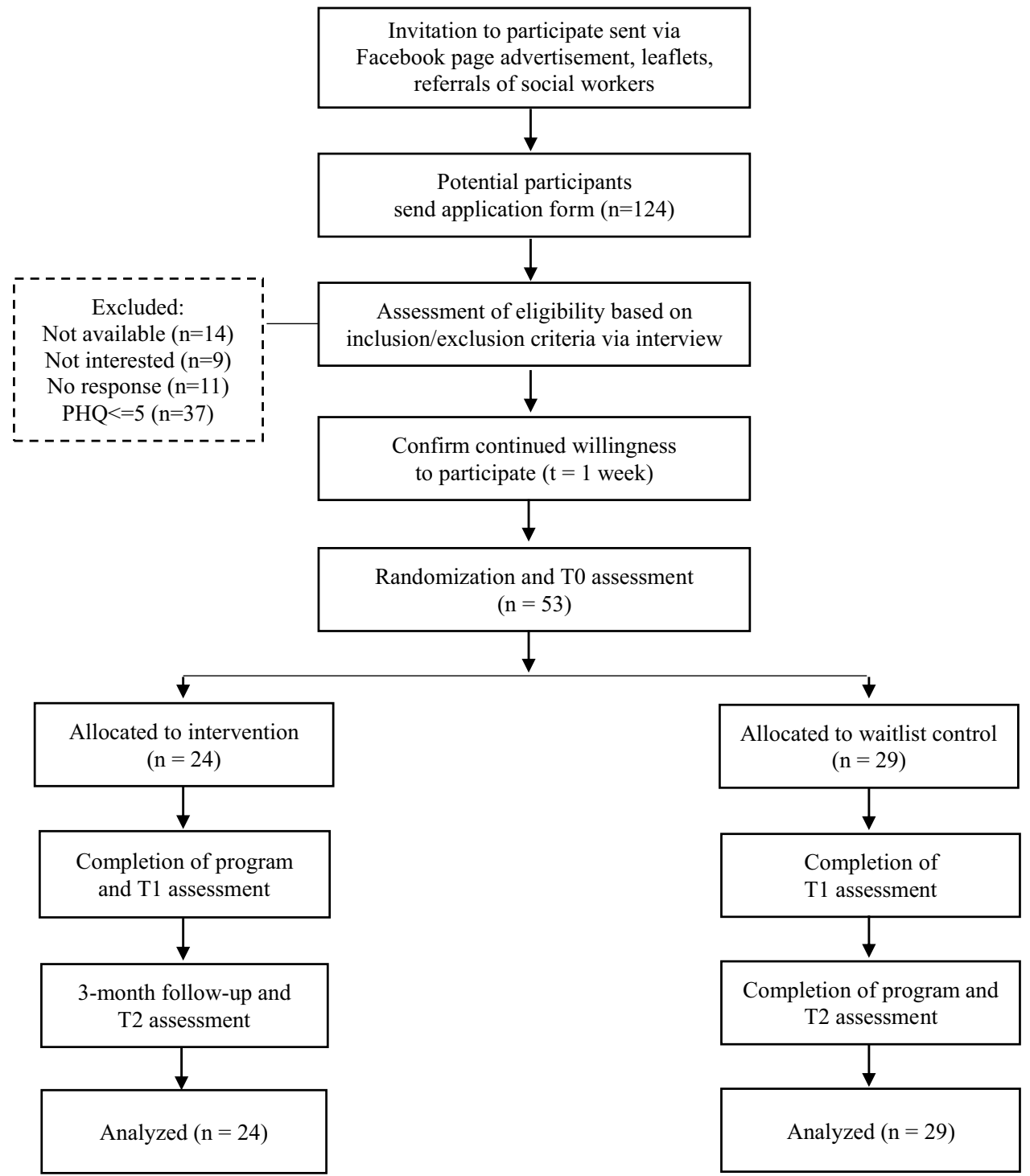

same protocol was further evaluated in two other studies for parents of children with ADHD symptomology and parents from economic disadvantaged families, respectively (Lo et al., 2019; Lo et al., 2020).

For the present study, the original six-session format was reduced to four sessions but covered the same mindfulness exercises, including body scan, mindful eating, mindful stretching, and mindful sitting. In addition, psychoeducation for interpersonal stress and fight or flight reaction, self-care plan, and discussions relevant to parenting were included (Bögels \& Restifo, 2014). Two additional mindfulness exercises were included in view of the special family and social context of the participants. First, "Finding the ground" was introduced and participants were offered additional choices for objects of attention as there was a concern that some participants might have some difficulty in focusing on their breath due to COVID-19, anxiety, panic, or post-traumatic stress (Williams, 2020). Second, we included the Soles of the Feet (SoF; Singh et al., 2011) practice which enables parents to manage their anger or other upsetting events by shifting the focus of attention to a neutral part of their body and dissipating the negative emotional arousal. This practice can be very useful for managing conflictual situations in family interactions.

\section{Waitlist Control}

Families in the waitlist group were instructed to continue with whatever programs and procedures they were using with their adolescents and young adults at the start of the study. The study protocol required the control group families to receive face-to-face training when training ended for the experimental group. However, because the second wave of COVID-19 infections in the city required precautionary 
measures to be undertaken, the control group families were offered two online workshops instead of face-to-face training.

\section{Instructors}

The instructors were doctoral-level social workers, psychologists, and a psychiatrist, all with foundational training in mindfulness-based cognitive therapy (MBCT). All had maintained a regular disciplined personal mindfulness practice.

\section{Incentive}

We provided supermarket coupons to parents who completed the outcome questionnaires twice (at T1 and T2, see "Measures") as compensation for time spent in data collection. Each coupon was worth 100 Hong Kong Dollars, which was equivalent to 13 US Dollars.

\section{Measures}

All outcomes were assessed at T0 (baseline pretest-before the intervention group joined the workshop), T1 (after the completion of the intervention group's program and the waitlist control group joined the workshop), and T2 (3-month follow-up after $\mathrm{T} 0$ for the intervention group). The following outcome measures were used in this study.

\section{Negative Emotions}

Three prominent emotions about social unrest were measured by items selected from a study by Halperin and ReifenTagar (2017), including the intensity of three negative emotions (hatred, anger, despair) using Likert-type scale ranging from 1 (not at all) to 10 (very strong). Cronbach's alpha for this study for total score was 0.88 .

\section{Depression Symptoms}

The Patient Health Questionnaire (PHQ-9, Kroenke et al., 2001) was used to measure symptoms of depression. This scale has nine items and assesses the nine major symptoms of depression in the last 2 weeks based on the criteria of major depressive episode in DSM-5. A cut-off score of 5 represents mild level of depression. Cronbach's alpha for this study for total score was 0.83 .

\section{Anxiety Symptoms}

The Generalized Anxiety Disorder (GAD-7, Kroenke et al., 2007) Scale was used for measuring symptoms of anxiety. This scale has seven items and assesses the seven major symptoms of anxiety in the last 2 weeks based on the criteria of generalized anxiety disorder in DSM-5. Cronbach's alpha for this study for total score was 0.92 .

\section{Post-traumatic Stress Symptoms}

The International Trauma Questionnaire (ITQ, Cloitre et al., 2018) was used to measure symptoms of post-traumatic stress disorder. It is a 6-item self-report measure of the major symptoms of post-traumatic stress based on the parent's experiences in the previous 1 month, based on the criteria of post-traumatic stress disorder in ICD-11. Cronbach's alpha for this study for total score was 0.88 .

\section{Family Functioning}

Family functioning was assessed by the Family Adaptation, Partnership, Growth, Affection, Resolve (Family APGAR, Smilkstein et al., 1982) Scale. The 5-item scale uses a 3 -point response scale $(0=$ hardly ever and $2=$ almost always). Cronbach's alpha for this study for total score was 0.91 .

\section{Family Conflict}

Family conflict was measured by the Conflict Tactics Scale (CTS, Straus, 1979), a self-report measure of behavioral assault or psychological aggression among family members. The scales have eight items, including three subscales: verbal conflict ( 1 item), physical conflict (5 items), and positive negotiation ( 2 items). Child-initiated conflicts and parent-self-initiated conflicts are assessed separately. Cronbach's alpha for this study for total score was 0.84 and 0.86 for child-initiated conflicts and parent-initiated conflicts, respectively. Those for physical conflict were 0.95 and 0.95 for child-initiated conflicts and parent-initiated conflicts, respectively. However, those for positive negotiation were only 0.57 and 0.72 for child-initiated conflicts and parentinitiated conflicts, respectively.

\section{Mindful Parenting}

The original Interpersonal Mindfulness in Parenting Scale includes 31 items that assess a parent's quality of mindfulness, specific to his or her family context (Duncan, 2007). The scale was validated based on a Hong Kong Chinese sample and a 23-item Chinese version has been developed (Lo et al., 2018a, b). In this study, we selected two subscales-Nonjudgmental Acceptance in Parenting (6 items) and Listening with Full Attention (4 items)—which were found to be sensitive to mindfulness-based interventions in previous studies. Cronbach's alpha for this study for total sub-scale scores was 0.90 and 0.89 for the subscales of 
nonjudgmental acceptance and listening with full attention, respectively.

\section{Exposure to Social Unrest}

This was measured by the modified Political Life Events Scale (Slone \& Halls, 1999). The original scale has 20 items and we excluded 6 items (such as "a security drill at school" and "time spent in a security shelter"), which were considered unsuitable in the Hong Kong context. Sample items used in this study include "harm to property as a result of political violence," "participation in a political demonstration," "witnessing an act of political violence," and "injury to a friend or acquaintance as a result of political violence." Cronbach's alpha for this study for total score was 0.78 .

\section{Program Fidelity}

Mindfulness-Based Interventions-Teaching Assessment Criteria was adopted to assess treatment fidelity of the parent program. It included six domains of competence in instructing a mindfulness program that might also apply to a brief mindfulness-based intervention (Crane et al., 2013). All sessions were audio recorded for assessing treatment fidelity. One of the four sessions (25\% of the total program) was randomly selected for each group. An independent reviewer who was an experienced teacher of mindfulness-based program with full professional training in MBCT rated the implementation fidelity of the present study.

\section{Attendance-Online Interviews}

After all workshops were completed, we invited all parents who completed at least three sessions of the workshop to attend a 30-min semi-structured online interview.

\section{Data Analyses}

The quantitative analyses focused on the outcome of the parenting program. Intervention effects were evaluated by comparing the intervention and waitlist control groups. Repeated measures ANOVA, with time (pretest and post-test) as the within-subject variable and group (treatment group and control group) as the between-subject variable, was used to detect effects of time, group, and time $\times$ group interactions for each of the outcome measures. All analyses were carried out according to the intention-to-treat approach. The participants' missing values were imputed using the lastobservation-carried-forward method. A two-sided $p$ value of 0.05 or less was considered statistically significant. In the case of significant results, effect sizes were calculated. Cohen (1988) suggested that $d=0.2$ be considered a small effect size, 0.5 a medium effect size, and 0.8 a large effect size. All quantitative analyses were performed using SPSS version 27.0.

For qualitative analyses, a process of inductive analysis was employed to derive concepts, themes, and models, through a detailed reading of interview data (Strauss \& Corbin, 1998; Thomas, 2006). Interviews were transcribed and analyzed using grounded theory analysis (Strauss \& Corbin, 1998). The researcher constantly moved between change mechanism of mindfulness-based intervention and understanding client's experiences of changes. A "bracketing" of assumptions and purposes of the study was required, especially during the early stages of analysis. "Reflexive validity" was met by constantly revisiting the original ideas and the formation of the categories (Stiles, 1993). The process of analysis was carried through repeated readings and interpretations of the interviews. Although it is often assumed that themes emerge from qualitative data, we agree with Braun and Clarke (2006) that themes are in fact interpretatively identified and are influenced by the researchers in terms of how the data are interpreted.

\section{Results}

\section{Preliminary Analyses at Baseline}

Parents from the intervention group had older children ( $M=17.13$ years old) when compared to the parents from the waitlist control group ( $M=15.06$ years old) $(t=2.86$, $p=0.096)$. On average, parents had 1.25 and 1.17 children in the intervention group and waitlist control group, respectively. Of all participants, $91.6 \%$ and $75.9 \%$ were mothers from the intervention group and waitlist control group, respectively. As reported in Table 1, no significant differences were found in all outcome measures at T0, including depression, anxiety, post-traumatic stress, negative emotions, family functioning, conflicts initiated by parents, and mindful parenting, except physical conflict initiated by child, $t(51)=3.92, p=0.05$. This showed that the randomization was successful, and physical conflict initiated by child should be considered a co-variant when necessary.

\section{Analyses of Outcome Measures}

We conducted $2 \times 2$ ANOVA and investigated time $\times$ group effects. Although parents from the mindfulness group reported reductions of mental health symptoms including depression, anxiety, post-traumatic stress, negative emotions, verbal conflict initiated by child, and verbal conflict initiated by parent reduced, physical conflict initiated by child and physical conflict initiated by parent increased. There was more physical conflict initiated by child but less physical conflict initiated by parent. There was less 
Table 1 Pretreatment evaluation between the treatment group and the waitlist control group

\begin{tabular}{|c|c|c|c|c|c|}
\hline Variables & Intervention $(n=24)$ & Control $(n=29)$ & $t$ & $\chi^{2}$ & $p$ \\
\hline Child $M_{\text {age }}(S D)$ & $17.13(4.87)$ & $15.06(4.77)$ & 2.86 & & .10 \\
\hline Number of children $(S D)$ & $1.25(.44)$ & $1.17(.47)$ & .38 & & .54 \\
\hline Parent sex & & & & 2.33 & .13 \\
\hline Male & 2 & 7 & & & \\
\hline Female & 22 & 22 & & & \\
\hline Depression & $8.38(2.93)$ & $7.86(2.25)$ & .52 & & .47 \\
\hline Anxiety & $7.96(3.77)$ & $8.59(4.38)$ & .31 & & .58 \\
\hline Post-traumatic stress & $5.88(3.79)$ & $6.28(3.56)$ & .16 & & .69 \\
\hline Negative emotions & $18.21(7.05)$ & $17.10(5.80)$ & .39 & & .53 \\
\hline Family functioning & $5.04(2.42)$ & $4.72(2.97)$ & .18 & & .68 \\
\hline Conflict (child initiate) & $6.54(3.02)$ & $7.83(3.31)$ & 2.15 & & .15 \\
\hline Verbal conflict & $1.58(1.10)$ & $1.72(1.36)$ & .17 & & .69 \\
\hline Physical conflict & $0.75(1.15)$ & $1.83(2.45)$ & 3.92 & & $.05^{*}$ \\
\hline Positive negotiation & $4.21(2.04)$ & $4.28(1.77)$ & .02 & & .90 \\
\hline Conflict (parent initiate) & $6.17(2.81)$ & $7.24(2.40)$ & 2.26 & & .14 \\
\hline Verbal conflict & $1.21(1.22)$ & $1.24(1.38)$ & .01 & & .93 \\
\hline Physical conflict & $1.04(1.49)$ & $1.07(1.49)$ & .02 & & .95 \\
\hline Positive negotiation & $3.92(2.19)$ & $4.93(1.96)$ & 3.17 & & .08 \\
\hline Mindful parenting & $31.88(6.84)$ & $30.48(6.45)$ & .58 & & .45 \\
\hline Non-judgmental acceptance & $12.13(3.22)$ & $11.83(2.59)$ & .14 & & .71 \\
\hline Full attention of children & $19.75(4.75)$ & $18.66(4.36)$ & .76 & & .39 \\
\hline Exposure to social unrest & $26.17(2.90)$ & $27.24(3.00)$ & 1.74 & & .19 \\
\hline
\end{tabular}

$* p<0.05$ positive negotiation initiated by child and more positive negotiation initiated by parent. Unexpectedly, there was a reduction in mindful parenting. However, less of the above changes reached the pre-determined level of significance in the analyses (all $p>0.05$, see Table 2).

We found parents with mild to severe depressive symptoms reported significant improvements were found in the intervention group when compared with the waitlist control group $(F[1,49]=4.41, p=0.04)$, with a moderate effect size $(d=0.54)$ (see Tables 2 and 3$)$. We further investigate whether child-initiated physical conflict acted as covariate to the change due to its significant betweengroup difference at baseline. A significant reduction in depression symptoms was found in the parents from the intervention group when compared to the waitlist control group $(F[1,49]=5.14, p=0.03)$, with a moderate effect size $(d=0.60)$ (see Table 3$)$.

Lastly, we conducted one-way ANOVA for the intervention group parents by comparing the pretest, the post-test, and 3-month follow-up. Marginal improvement in depression $(F=2.72, p=0.07, d=0.52)$ was found (see Table 4$)$. For other outcomes, there were no significant time $\times$ group effects between $\mathrm{T} 0$ and $\mathrm{T} 2$.

\section{Attendance and Implementation Fidelity}

Among the completers, the attendance rate was $91.50 \%$ for the intervention group parents, $78.1 \%$ for the waitlist group parents, and an overall attendance of $83.66 \%$. The attrition rate, defined as attendance in at least three or four sessions of the program, was $3.92 \%$ for the intervention group, $19.61 \%$ for the waitlist group, and an overall attrition rate of $11.76 \%$.

For the implementation fidelity, the score was 4.17 out of 6.

\section{Parent's Subjective Experiences and Perceived Benefits from the Program}

Fourteen parents participated in online interviews and we classified their experiences into two broad areas: helpfulness of the program and changes after the program.

\section{Helpfulness of the Program}

Some participants observed that sharing their practice with other parents offered them new experiences that brought new awareness and insights. Such experiences ranged from the 
Table 2 Measures over time for the intervention group and the waitlist control group

\begin{tabular}{|c|c|c|c|c|c|c|c|c|}
\hline \multirow[b]{2}{*}{ Measure } & \multicolumn{2}{|c|}{$\begin{array}{l}\text { Treatment } \\
(n=24)\end{array}$} & \multicolumn{2}{|c|}{$\begin{array}{l}\text { Control } \\
(n=29)\end{array}$} & \multicolumn{4}{|c|}{$\begin{array}{l}\text { Repeated measures ANOVA } \\
\text { (T1 vs. T2) }\end{array}$} \\
\hline & $M$ & $S D$ & $M$ & $S D$ & Effect & $F$ & $d f$ & $d$ \\
\hline \multicolumn{9}{|c|}{ Depression } \\
\hline Time 1 & 8.38 & 2.93 & 7.86 & 2.25 & Group & .22 & 1,51 & \\
\hline \multirow[t]{2}{*}{ Time 2} & 6.46 & 4.10 & 7.64 & 3.48 & Time & 3.84 & 1,51 & \\
\hline & & & & & Group $\times$ Time & 2.40 & 1,51 & \\
\hline \multicolumn{9}{|l|}{ Anxiety } \\
\hline Time 1 & 7.96 & 3.77 & 8.59 & 4.38 & Group & .21 & 1,51 & \\
\hline \multirow[t]{2}{*}{ Time 2} & 6.92 & 4.29 & 7.19 & 3.79 & Time & $4.87 *$ & 1,51 & .49 \\
\hline & & & & & Group $\times$ Time & 2.40 & 1,51 & \\
\hline \multicolumn{9}{|c|}{ Post-traumatic stress } \\
\hline Time 1 & 5.88 & 3.79 & 6.28 & 3.56 & Group & .36 & 1,51 & \\
\hline \multirow[t]{2}{*}{ Time 2} & 4.50 & 3.76 & 5.21 & 3.93 & Time & $6.38 *$ & 1,51 & .58 \\
\hline & & & & & Group $\times$ Time & .10 & 1,51 & \\
\hline \multicolumn{9}{|c|}{ Negative emotion } \\
\hline Time 1 & 18.21 & 7.05 & 17.10 & 5.80 & Group & 1.07 & 1,51 & \\
\hline \multirow[t]{2}{*}{ Time 2} & 16.79 & 7.32 & 14.47 & 6.96 & Time & $5.55^{*}$ & 1,51 & .64 \\
\hline & & & & & Group $\times$ Time & .50 & 1,51 & \\
\hline \multicolumn{9}{|c|}{ Family functioning } \\
\hline Time 1 & 5.04 & 2.42 & 4.72 & 2.97 & Group & 2.15 & 1,51 & \\
\hline \multirow[t]{2}{*}{ Time 2} & 5.73 & 2.09 & 4.03 & 3.23 & Time & .00 & 1,51 & \\
\hline & & & & & Group $\times$ Time & $4.41 *$ & 1,51 & .54 \\
\hline \multicolumn{9}{|c|}{ Conflict (child-initiated) } \\
\hline \multicolumn{9}{|l|}{ Total } \\
\hline Time 1 & 6.54 & 3.02 & 6.17 & 2.81 & Group & 3.25 & 1,51 & \\
\hline \multirow[t]{2}{*}{ Time 2} & 6.31 & 3.00 & 6.38 & 3.20 & Time & .15 & 1,51 & \\
\hline & & & & & Group $\times$ Time & .01 & 1,51 & \\
\hline \multicolumn{9}{|c|}{ Verbal conflict } \\
\hline Time 1 & 1.58 & 1.10 & 1.72 & 1.36 & Group & .10 & 1,51 & \\
\hline \multirow[t]{2}{*}{ Time 2} & 1.40 & 1.05 & 1.43 & 1.10 & Time & 2.34 & 1,51 & \\
\hline & & & & & Group $\times$ Time & .11 & 1,51 & \\
\hline \multicolumn{9}{|c|}{ Physical conflict } \\
\hline Time 1 & 0.75 & 1.15 & 1.83 & 2.45 & Group & 3.04 & 1,51 & \\
\hline Time 2 & 1.06 & 1.55 & 1.76 & 3.03 & Time & .12 & 1,51 & \\
\hline & & & & & Group $\times$ Time & .30 & 1,51 & \\
\hline Negotiatic & & & & & & & & \\
\hline Time 1 & 4.21 & 2.04 & 3.92 & 2.19 & Group & .70 & 1,51 & \\
\hline Time 2 & 3.85 & 2.15 & 4.27 & 2.10 & Time & .04 & 1,51 & \\
\hline & & & & & Group $\times$ Time & 1.04 & 1,51 & \\
\hline Conflict ( & initiated & & & & & & & \\
\hline Total & & & & & & & & \\
\hline Time 1 & 6.17 & 2.81 & 7.24 & 2.40 & Group & 2.68 & 1,51 & \\
\hline Time 2 & 6.38 & 3.20 & 7.59 & 3.55 & Time & .37 & 1,51 & \\
\hline & & & & & Group $\times$ Time & .02 & 1,51 & \\
\hline Verbal cor & & & & & & & & \\
\hline Time 1 & 1.21 & 1.22 & 1.24 & 1.38 & Group & .06 & 1,51 & \\
\hline Time 2 & 1.04 & 1.17 & 1.14 & 1.09 & Time & .43 & 1,51 & \\
\hline & & & & & Group $\times$ Time & .02 & 1,51 & \\
\hline Physical c & & & & & & & & \\
\hline Time 1 & 1.04 & 1.49 & 1.07 & 1.49 & Group & .28 & 1,51 & \\
\hline
\end{tabular}


Table 2 (continued)

\begin{tabular}{|c|c|c|c|c|c|c|c|c|}
\hline \multirow[b]{2}{*}{ Measure } & \multicolumn{2}{|c|}{$\begin{array}{l}\text { Treatment } \\
(n=24)\end{array}$} & \multicolumn{2}{|c|}{$\begin{array}{l}\text { Control } \\
(n=29)\end{array}$} & \multicolumn{4}{|c|}{$\begin{array}{l}\text { Repeated measures ANOVA } \\
\text { (T1 vs. T2) }\end{array}$} \\
\hline & $M$ & $S D$ & $M$ & $S D$ & Effect & $F$ & $d f$ & $d$ \\
\hline \multirow[t]{2}{*}{ Time 2} & 1.06 & 1.76 & 1.52 & 2.89 & Time & .51 & 1,51 & \\
\hline & & & & & Group $\times$ Time & .43 & 1,51 & \\
\hline \multicolumn{9}{|c|}{ Negotiation } \\
\hline Time 1 & 3.92 & 2.19 & 4.93 & 1.96 & Group & 3.21 & 1,51 & \\
\hline \multirow[t]{2}{*}{ Time 2} & 4.27 & 2.10 & 4.93 & 2.02 & Time & .30 & 1,51 & \\
\hline & & & & & Group $\times$ Time & .30 & 1,51 & \\
\hline \multicolumn{9}{|c|}{ Mindful parenting } \\
\hline \multicolumn{9}{|c|}{ Acceptance } \\
\hline Time 1 & 12.13 & 3.22 & 11.83 & 2.59 & Group & .12 & 1,51 & \\
\hline \multirow[t]{2}{*}{ Time 2} & 11.31 & 3.51 & 12.10 & 2.58 & Time & .45 & 1,51 & \\
\hline & & & & & Group $\times$ Time & 1.86 & 1,51 & \\
\hline \multicolumn{9}{|l|}{ Attention } \\
\hline Time 1 & 19.75 & 4.75 & 18.66 & 4.36 & Group & .44 & 1,51 & \\
\hline \multirow[t]{2}{*}{ Time 2} & 17.96 & 5.03 & 17.53 & 4.57 & Time & $6.38 *$ & 1,51 & .70 \\
\hline & & & & & Group $\times$ Time & .34 & 1,51 & \\
\hline
\end{tabular}

$* p<0.05$

practice itself, the impact of the practice on their own body and mind, and the sharing and dialogues with other parent participants.

The mindful eating exercise is rather impressive because you do have a physical (and visual) aid for the practice while others do not. (Parent \#3)

As a participant and an observer, I listened to other parents who have emotional struggles. Parents can discuss when there is a strong sense of companionship. (Parent \#5) Add an extra space between quotes

It is very comfortable and relaxing because I do not need to think about the happenings in life and leave my hassles aside. While attending to myself, I could really feel my body and brain all relaxed. (Parent \#1)

\section{Changes After the Program}

Participants shared that following the mindful parenting workshop, they were more capable of regulating their own negative emotions and became less reactive in family conflicts. Some parents further revealed that such changes were grounded in their learning though mindfulness exercises that offered new perspectives to the parenting relationship and their adolescent children.

I think it was helpful when I get calmer. There was more space to listen to my husband's nagging. If I get irritated and impatient, it was not helpful for the situ- ation and the relationship. (Parent \#10) Add an extra space between quotes

One time, I was quarrelling with my son and then I actually found a place to take two breaths. It really cooled down my anger, and the situation became not a big deal. (Parent \#11)Add an extra space between quotes

When my children tell me some problem, I usually give solutions. However, there should be occasions that I should listen and do not say anything. They would then tell me more. (Parent \#2)Add an extra space between quotes

Like picking grapes in mindful stretching, I need to understand my own limitations. It easily reminds me of that everyone has limitations, where there needs to be accept and to adjust expectations. This can apply to (my relationship) with children. (Parent \#9)Add an extra space between quotes

Finding the ground and loving kindness exercises ... give me peace in mind; that means, I blame others and myself less. (Parent \#13)Add an extra space between quotes There was an exercise about observing our children ... when I look into him in details and am aware of my children as a person . . . Just like a black spot on a white paper, people do have something not having done well. I am aware that I used to focus on the bad qualities ... I did not see him as a whole (in the past). (Parent \#7)Add an extra space between quotes 
Table 3 Measures over time for the intervention group and the waitlist control group (conflict initiated from both child and parent as covariates)

\begin{tabular}{|c|c|c|c|c|c|c|c|c|}
\hline \multirow[b]{2}{*}{ Measure } & \multicolumn{2}{|c|}{$\begin{array}{l}\text { Treatment } \\
(n=24)\end{array}$} & \multicolumn{2}{|c|}{$\begin{array}{l}\text { Control } \\
(n=29)\end{array}$} & \multicolumn{4}{|c|}{$\begin{array}{l}\text { Repeated measures ANOVA } \\
\text { (T1 vs. T2) }\end{array}$} \\
\hline & $M$ & $S D$ & $M$ & $S D$ & Effect & $F$ & $d f$ & $d$ \\
\hline \multicolumn{9}{|c|}{ Depression } \\
\hline Time 1 & 8.38 & 2.93 & 7.86 & 2.25 & Group & .37 & 1,49 & \\
\hline \multirow[t]{2}{*}{ Time 2} & 6.46 & 4.10 & 7.64 & 3.48 & Time & $4.86^{*}$ & 1,49 & .58 \\
\hline & & & & & Group $\times$ Time & $5.14 *$ & 1,49 & .60 \\
\hline \multicolumn{9}{|l|}{ Anxiety } \\
\hline Time 1 & 7.96 & 3.77 & 8.59 & 4.38 & Group & 1.21 & 1,49 & \\
\hline \multirow[t]{2}{*}{ Time 2} & 6.92 & 4.29 & 7.19 & 3.79 & Time & 2.27 & 1,49 & \\
\hline & & & & & Group $\times$ Time & .18 & 1,49 & \\
\hline \multicolumn{9}{|c|}{ Post-traumatic stress } \\
\hline Time 1 & 5.88 & 3.79 & 6.28 & 3.56 & Group & .55 & 1,49 & \\
\hline \multirow[t]{2}{*}{ Time 2} & 4.50 & 3.76 & 5.21 & 3.93 & Time & $5.49 *$ & 1,49 & .63 \\
\hline & & & & & Group $\times$ Time & .95 & 1,49 & \\
\hline \multicolumn{9}{|c|}{ Negative emotion } \\
\hline Time 1 & 18.21 & 7.05 & 17.10 & 5.80 & Group & .49 & 1,49 & \\
\hline \multirow[t]{2}{*}{ Time 2} & 16.79 & 7.32 & 14.47 & 6.96 & Time & .57 & 1,49 & \\
\hline & & & & & Group $\times$ Time & .25 & 1,49 & \\
\hline \multicolumn{9}{|c|}{ Family functioning } \\
\hline Time 1 & 5.04 & 2.42 & 4.72 & 2.97 & Group & 1.08 & 1,49 & \\
\hline \multirow[t]{2}{*}{ Time 2} & 5.73 & 2.09 & 4.03 & 3.23 & Time & .32 & 1,49 & \\
\hline & & & & & Group $\times$ Time & 2.80 & 1,49 & \\
\hline
\end{tabular}

Conflict (child-initiated)

Total

$\begin{array}{ccccc}\text { Time 1 } & 6.54 & 3.02 & 6.17 & 2.81 \\ \text { Time 2 } & 6.31 & 3.00 & 6.38 & 3.20 \\ \text { Verbal conflict } & & & & \\ \text { Time 1 } & 1.58 & 1.10 & 1.72 & 1.36 \\ \text { Time 2 } & 1.40 & 1.05 & 1.43 & 1.10\end{array}$

Physical conflict

$\begin{array}{lllll}\text { Time } 1 & 0.75 & 1.15 & 1.83 & 2.45 \\ \text { Time } 2 & 1.06 & 1.55 & 1.76 & 3.03 \\ \text { Negotiation } & & & & \\ \text { Time } 1 & 4.21 & 2.04 & 3.92 & 2.19 \\ \text { Time } 2 & 3.85 & 2.15 & 4.27 & 2.10\end{array}$

Conflict (parent-initiated)

Total

$\begin{array}{lllll}\text { Time } 1 & 6.17 & 2.81 & 7.24 & 2.40 \\ \text { Time } 2 & 6.38 & 3.20 & 7.59 & 3.55 \\ \text { Verbal conflict } & & & & \\ \text { Time } 1 & 1.21 & 1.22 & 1.24 & 1.38 \\ \text { Time 2 } & 1.04 & 1.17 & 1.14 & 1.09\end{array}$

Physical conflict

$\begin{array}{lllll}\text { Time 1 } & 1.04 & 1.49 & 1.07 & 1.49 \\ \text { Time 2 } & 1.06 & 1.76 & 1.52 & 2.89 \\ \text { Negotiation } & & & & \\ \text { Time 1 } & 3.92 & 2.19 & 4.93 & 1.96 \\ \text { Time 2 } & 4.27 & 2.10 & 4.93 & 2.02\end{array}$

Mindful parenting

Acceptance

Time 1

12.13

3.22

11.83

2.59

Group

.46

1,49 
Table 3 (continued)

\begin{tabular}{|c|c|c|c|c|c|c|c|c|}
\hline \multirow[b]{2}{*}{ Measure } & \multicolumn{2}{|c|}{$\begin{array}{l}\text { Treatment } \\
(n=24)\end{array}$} & \multicolumn{2}{|c|}{$\begin{array}{l}\text { Control } \\
(n=29)\end{array}$} & \multicolumn{4}{|c|}{$\begin{array}{l}\text { Repeated measures ANOVA } \\
\text { (T1 vs. T2) }\end{array}$} \\
\hline & $M$ & $S D$ & $M$ & $S D$ & Effect & $F$ & $d f$ & $d$ \\
\hline \multirow[t]{2}{*}{ Time 2} & 11.31 & 3.51 & 12.10 & 2.58 & Time & 1.28 & 1,49 & \\
\hline & & & & & Group $\times$ Time & .17 & 1,49 & \\
\hline \multicolumn{9}{|l|}{ Attention } \\
\hline Time 1 & 19.75 & 4.75 & 18.66 & 4.36 & Group & .01 & 1,49 & \\
\hline \multirow[t]{2}{*}{ Time 2} & 17.96 & 5.03 & 17.53 & 4.57 & Time & 2.39 & 1,49 & \\
\hline & & & & & Group $\times$ Time & .25 & 1,49 & \\
\hline
\end{tabular}

$* p<0.05$

Table 4 One-way ANOVA on measures of the intervention group $(n=24)$

\begin{tabular}{|c|c|c|c|c|c|c|c|c|c|c|}
\hline \multirow[b]{2}{*}{ Measures } & \multicolumn{2}{|c|}{$\mathrm{T} 1$ versus $\mathrm{T} 2$} & \multicolumn{2}{|c|}{$\mathrm{T} 2$ versus $\mathrm{T} 3$} & \multicolumn{3}{|c|}{$\mathrm{T} 1$ versus $\mathrm{T} 3$} & \multirow[b]{2}{*}{$d f$} & \multirow[b]{2}{*}{$p$} & \multirow[b]{2}{*}{$d$} \\
\hline & $\Delta *$ & $S E$ & $\Delta^{*}$ & $S E$ & $\Delta^{*}$ & $S E$ & $F$ & & & \\
\hline Depression & -1.92 & 1.02 & -.25 & 1.02 & -2.17 & 1.02 & 2.72 & 2,69 & .07 & \\
\hline Anxiety & -1.04 & 1.21 & -.50 & 1.21 & -1.54 & 1.21 & .85 & 2,69 & .43 & \\
\hline Post-traumatic stress & -1.38 & 1.12 & -.10 & 1.12 & -1.48 & 1.12 & 1.08 & 2,69 & .34 & \\
\hline Negative emotions & -1.42 & 2.06 & -1.04 & 2.06 & -2.46 & 2.06 & .72 & 2,69 & .49 & \\
\hline Family functioning & .69 & .65 & .25 & .65 & .94 & .65 & 1.12 & 2,69 & .33 & \\
\hline Conflict (child-initiate) & -.23 & .82 & .04 & .82 & -.19 & .82 & .05 & 2,69 & .96 & \\
\hline Verbal conflict & -.19 & .30 & -.29 & .30 & -.48 & .30 & 1.27 & 2,69 & .29 & \\
\hline Physical conflict & .31 & .36 & -.54 & .36 & -.23 & .36 & 1.14 & 2,69 & .33 & \\
\hline Negotiation & -.35 & .60 & .88 & .60 & .52 & .60 & 1.07 & 2,69 & .35 & \\
\hline Conflict (parent-initiate) & .21 & .82 & -.33 & .82 & -.13 & .82 & .08 & 2,69 & .92 & \\
\hline Verbal conflict & -.17 & .33 & -.19 & .33 & -.35 & .33 & .59 & 2,69 & .56 & \\
\hline Physical conflict & .02 & .41 & -.65 & .41 & -.63 & .41 & 1.59 & 2,69 & .21 & \\
\hline Negotiation & .35 & .63 & .50 & .63 & .85 & .63 & .92 & 2,69 & .40 & \\
\hline Mindfulness & -2.60 & 2.17 & .27 & 2.17 & -2.33 & 2.17 & .87 & 2,69 & .42 & \\
\hline Acceptance & -.81 & .96 & .08 & .96 & -.73 & .96 & .44 & 2,69 & .65 & \\
\hline Attention & -1.79 & 1.40 & .19 & 1.40 & -1.60 & 1.40 & .99 & 2,69 & .38 & \\
\hline
\end{tabular}

I feel I have been internalized . . . less agitated and inpatient. Before that, I did all the talking and did not let others talk. Because of insufficient time, I was in a rush in relating with my husband and children, and they needed to follow my instruction. After learning mindfulness, I have slowed down. (Parent \#14)Add an extra space between quotes

Sometimes I sensed the body was uncomfortable, I felt like my brain in automatic mode. Now, at a time point, I would stop for a while before rushing to other next moment (or tasks one by one) so that my tantrum would not explode. It is not worthwhile to damage the relationship with the daughter. (Parent \#6)Add an extra space between quotes

My relationship with my daughter has been improved. I do not pose myself like an authority. I would treat her as a friend. We now get along better. (Parent \#1)

\section{Discussion}

There is increasing social unrest in many countries around the world, but few studies have been conducted to investigate whether a brief mindfulness-based program would support individuals in this specific context. One study from Israel showed that after being presented with anger-inducing information related to political conflict, adult participants in a mindfulness workshop were more supportive of conciliatory policies, with the effects being mediated by a reduction in perceived threat and improvement in emotion regulation (Alkoby et al., 2017). However, Alkoby et al.'s study was not designed for parents. In this study, we evaluated the effects of a brief 4-session mindful parenting program in Hong Kong, a city that had experienced social unrest for a year at the time of study, and investigated if it can strengthen their emotion regulation, promote better mental health, and reduce family conflicts. 
As a consequence of the changing social, political, and pandemic conditions in the city, this study encountered two major challenges during the study period. First, the social unrest aroused families' suspicion and sensitivity about data collection, and they were very reluctant to reveal their personal data to the researchers. To manage this, we adopted an indicated preventive approach and used a self-reported depression screening before the start of the intervention. Second, some parents hesitated to participate in a face-toface program due to the COVID-19 pandemic. A ban on gathering and social distancing created hurdles for the project team to recruit more parents to attend the workshops. Collaborators at secondary schools had been preoccupied with adjustment in academic study and placed less priority in arranging parent programs. The number of participants recruited for the study was much smaller than our planned sample size. Further studies in this context should be prepared for these challenges in recruitment and develop strategies to reduce the parent's resistance in data collection.

In spite of these challenges, results of the present study showed that participants of our mindfulness program reported significant improvements in family functioning, after intervention when compared with the waitlist-controlled parents. When we controlled the variable of childinitiated physical conflict, there was a significant reduction in depressive symptoms of parents after completing the mindful parenting program, when compared to parents in the waitlist control group. When we considered the changes in the intervention group only, we found marginal improvement in depression from pre-intervention baseline to 3-month follow-up. These results provide suggestive evidence that parents of adolescents and young adults with depressive symptoms during social unrest could benefit from a brief mindfulness-based intervention program.

The qualitative data indicated that parents began to cultivate a sense of calmness and security during and following the mindfulness-based parenting program. They also developed positive reappraisals of their family relationships that would likely assist them to achieve resolution of intergroup conflict within the family. In addition, the mindfulness-based program offered parents strategies for regulating their emotions and in reducing their reactive responses when facing conflict situations within the family. Collectively, these qualitative findings, together with the quantitative evidence, suggest that this mindfulness-based program may be a viable option for supporting parents during social unrest.

\section{Limitations and Future Research}

The findings of this study should be informed by its limitations, most of which were the result of the social unrest in Hong Kong city during the study period. We found medium sizes of effect in two outcome measures only and such benefits were relatively small when compared to extant studies that used similar dosages of mindfulnessbased programs to parents of children with ADHD, and those from disadvantaged families (Lo et al., 2019; Lo et al., 2020). Such differences may be due to the context of the present study, when social unrest was experienced by the participants during the course of the study. Indeed, many parents and families anecdotally reported still being overwhelmed by the political protests and media coverage. In addition, the city was facing another wave of COVID-19 pandemic while the last set of data was being collected. These external contingencies resulted in limitations to the study design not only with regard to participant recruitment but also the extent of data that could be collected, both in terms of breadth of the information and the duration of the data collection period. On a positive note, the present study provides salutary information that can inform future research under social unrest and pandemic conditions.

The present study was limited by the use of the waitlist control design because it does not permit multiple treatments to be assessed against each other and raises the possibility that the purported significant findings could have resulted from a general treatment effect. Furthermore, the waitlist-control group of parents had been informed that they will not be receiving the mindfulness-based program until the completion of training of the intervention group. This inevitably means that these parents were not blind to the experimental and control conditions. Future research should include an active control condition that includes features that look like the mechanics of mindful parenting programs but excludes the specific mechanisms that produce the effects of the active program.

Our study may have suffered from common method bias that is typically a problem in studies based on self-reported measures (Podsakoff et al., 2003). In this study, because multiple constructs were measured using rating scales, the results could have been due to how the measurement instruments were presented rather than to the constructs being measured. Relying only on rating scales may lead to spurious correlations among the items measuring multiple constructs as a result of response styles, social desirability, priming effects which may be independent from the true correlations among the constructs being measured (Podsakoff et al., 2003). Future research under non-social unrest conditions should include multiple methods or instruments (e.g., rating scales, direct observations, and performance measures).

Author Contribution HHML designed the study, monitored the study implementation, and wrote the paper. ENSL was involved in preparation of funding proposal, design of the study, and delivered special 
training to the program instructors. CHLT was involved in preparation of funding proposal and coordination with collaborators. SWN contributed to the design of the study and provided consultation to the project implementation. SHWC and FHL were involved in statistical analyses. ETW, EWYW, GOCW, WCC, and AWKT contributed to the implementation of the parent workshops. NNS delivered special training to the program instructors, and provided advice and editing of the final manuscript.

Funding This study was supported by the Policy Innovation and Coordination Office, The Government of the Hong Kong Special Area Region, Public Policy Research Funding Scheme (Special Round) (SR2020.A6.004).

Data Availability The data that support the findings of this study are available from the corresponding author upon reasonable request.

\section{Declarations}

Ethics Approval and Consent to Participate Ethical approval for this study has been obtained from the Human Subjects Ethics Sub-Committee of The Hong Kong Polytechnic University. The research team explained all information about the study in a briefing session and all participants signed a written consent form.

Conflict of Interest The authors declare no competing interests.

\section{References}

Alkoby, A., Halperin, E., Tarrasch, R., \& Levit-Binnun, N. (2017). Increased support for political compromise in the Israeli-Palestinian conflict following an 8-week mindfulness workshop. Mindfulness, 8, 1345-1353.

Al-Krenawi, A., \& Graham, J. R. (2012). The impact of political violence on psychosocial functioning of individuals and families. Child \& Adolescent Mental Health, 17, 14-22.

American Psychiatric Association. (2013). Diagnostic and statistical manual of mental disorders (5th ed.). American Psychiatric Publishing.

Banks, K., Newman, E., \& Saleem, J. (2015). An overview of the research on mindfulness-based interventions for treating symptoms of posttraumatic stress disorder: A systematic review. Journal of Clinical Psychology, 71, 935-963.

Bishop, S. R., Lau, M., Shapiro, S., Carlson, L., Anderson, N. D., Carmody, J., Segal, Z. V., Abbey, S., Speca, M., Velting, D., \& Devins, G. (2004). Mindfulness: A proposed operational definition. Clinical Psychology: Science and Practice, 11, 230-241.

Bögels, S. M., \& Restifo, K. (2014). Mindful parenting: A guide for mental health practitioners. Springer.

Braun, V., \& Clarke, V. (2006). Using thematic analysis in psychology. Qualitative Research in Psychology, 3(2), 77-101.

Burgdorf, V., Szabó, M., \& Abbott, M. J. (2019). The effect of mindfulness interventions for parents on parenting stress and youth psychological outcomes: A systematic review and meta-analysis. Frontiers in Psychology, 10, 1336. https://doi.org/10.3389/fpsyg. 2019.01336

Čehajić-Clancy, S., Goldenberg, A., Gross, J. J., \& Halperin, E. (2016). Social-psychological interventions for intergroup reconciliation: An emotion regulation perspective. Psychological Inquiry, 27(2), $73-88$.
Chambers, R., Gullone, E., \& Allen, N. B. (2009). Mindful emotional regulation: An integrative review. Clinical Psychology Review, 29(6), 560-572.

Chan, C. S., Wong, J. W. S., \& Poon, C. (in review). When politics and family collide: A two-wave prospective study. https://doi.org/10. 31234/osf.io/8uetg

Chaplin, T. M., Turpyn, C. C., Fischer, S., Martelli, A. M., Ross, C. E., Leichtweis, R. N., Miller, A. B., \& Sinha, R. (2021). Parentingfocused mindfulness intervention reduces stress and improves parenting in highly stressed mothers of adolescents. Mindfulness, 12(2), 450-462.

Coatsworth, J. D., Duncan, L. G., Nix, R. L., Greenberg, M. T., Gayles, J. G., Bamberger, K. T., Berrena, E., \& Demi, M. A. (2015). Integrating mindfulness with parent training: Effects of the Mindfulness-Enhanced Strengthening Families Program. Developmental Psychology, 51, 26-35.

Cohen, J. (1988). Statistical power analysis for the behavioral sciences (2nd ed.). Lawrence Erlbaum Associates.

Cloitre, M., Shevlin, M., Brewin, C. R., Bisson, J. I., Roberts, N. P., Maercker, A., Karatzias, T., \& Hyland, P. (2018). The International Trauma Questionnaire: Development of a self-report measure of ICD-11 PTSD and complex PTSD. Acta Psychiatrica Scandinavica, 138(6), 536-546. https://doi.org/10.1111/ acps. 12956

Crane, R. S., Eames, C., Kuyken, W., Hastings, R. P., Williams, J. M. G., Bartley, T., Evans, A., Silverton, S., Soulsby, J. G., \& Surawy, C. (2013). Development and validation of the mindfulness-based interventions-teaching assessment criteria (MBI: TAC). Assessment, 20, 681-688.

Cummings, E. M., Taylor, L. K., Merrilees, C. E., Goeke-Morey, M. C., \& Shirlow, P. (2016). Emotional insecurity in the family and community and youth delinquency in Northern Ireland. Journal of Child Psychology and Psychiatry, 57, 47-54.

De Jong, J. T. V. M., Berckmoes, L. H., Kohrt, B. A., Song, S. J., Tol, W. A., \& Reis, R. (2015). A public health approach to address the mental health burden of youth in situations of political violence and humanitarian emergencies. Current Psychiatry Reports, 17, 60. https://doi.org/10.1007/s11920-015-0590-0

Dubow, E. F., Huesmann, L. R., Boxer, P., Landau, S., Dvir, S., Shikaki, K., \& Ginges, J. (2012). Exposure to political conflict and violence and posttraumatic stress in Middle East youth: Protective factors. Journal of Clinical Child \& Adolescent Psychology, 41, 402-416.

Duncan, L. G. (2007). Assessment of mindful parenting among parents of early adolescents: Development and validation of the Interpersonal Mindfulness in Parenting scale (Unpublished dissertation). The Pennsylvania State University

Goldenberg, A., Enav, Y., Halperin, E., Saguy, T., \& Gross, J. J. (2017). Emotional compensation in parents. Journal of Experimental Social Psychology, 69, 150-155.

Gordon, R. (1983). An operational classification of disease prevention. Public Health Reports, 98, 107-109.

Gu, J., Strauss, C., Bond, R., \& Cavanagh, K. (2015). How do mindfulness-based cognitive therapy and mindfulness-based stress reduction improve mental health and wellbeing? A systematic review and meta-analysis of mediation studies. Clinical Psychology Review, 37, 1-12.

Gutentag, T., Halperin, E., Porat, R., Bigman, Y. E., \& Tamir, M. (2017). Successful emotion regulation requires both conviction and skill: Beliefs about the controllability of emotions, reappraisal, and regulation success. Cognition and Emotion, $31,1225-1233$.

Halperin, E. (2015). Collective emotions and emotion regulation in intractable conflicts. In C. V. Scheve \& M. Salmela (Eds.), Collective emotions (pp. 281-298). Oxford University Press. 
Halperin, E., \& Reifen-Tagar, M. (2017). Emotions in conflicts: Understanding emotional processes sheds light on the nature and potential resolution of intractable conflicts. Current Opinion in Psychology, 17, 94-94.

Herd, T., \& Kim-Spoon, J. (2021). A systematic review of associations between adverse peer experiences and emotion regulation in adolescence. Clinical Child and Family Psychology Review, 24(1), 141-163.

Ho, P. S. Y., Jackson, S., \& Kong, S. S. (2018). Speaking against silence: Finding a voice in Hong Kong Chinese families through the umbrella movement. Sociology, 52, 966-982.

Hummert, M. L. (2012). Challenges and opportunities for communication between age groups. In H. Giles (Ed.), The handbook of intergroup communication (pp. 223-236). Routledge.

Kahana, S. Y., Feeny, N. C., Youngstrom, E. A., \& Drotar, D. (2006). Posttraumatic stress in youth experiencing illnesses and injuries. Traumatology, 12, 148-161.

Kroenke, K., Spitzer, R. L., \& Williams, J. B. (2001). The PHQ9: Validity of a brief depression severity measure. Journal of General Internal Medicine, 16, 606-613.

Kroenke, K., Spitzer, R. L., Williams, J. B., Monahan, P. O., \& Lowe, B. (2007). Anxiety disorders in primary care: Prevalence, impairment, comorbidity, and detection. Annals of Internal Medicine, 146, 317-325.

Lam-Knott, S. (2018). Anti-hierarchical activism in Hong Kong: The post-80s youth. Social Movement Studies, 17, 464-470. https:// doi.org/10.1080/14742837.2018.1427055

Lippold, M. A., Duncan, L. G., Coatsworth, J. D., Nix, R. L., \& Greenberg, M. T. (2015). Understanding how mindful parenting may be linked to mother-adolescent communication. Journal of Youth and Adolescence, 44, 1663-1673.

Lo, H. H. M., Chan, S. K. C., Szeto, M. P., Chan, C. Y. H., \& Choi, C. W. (2017). A feasibility study of a brief mindfulness-based program for parents of children with developmental disabilities. Mindfulness, 8, 1665-1673. https://doi.org/10.1007/ s12671-017-0741-y

Lo, H. H. M., Hui, M., \& Leung, M. (2018). Mindful parenting group for secondary school parents: Research report and practice handbook. Hong Kong Children \& Youth Services.

Lo, H. H. M., Yeung, J. W. K., Duncan, L. G., Ma, Y., Siu, A. F. Y., Chan, S. K. C., Choi, C. W., Szeto, M. P., Chow, K. K. W., \& Ng, S. M. (2018b). Validating of the Interpersonal Mindfulness in Parenting Scale in Hong Kong Chinese. Mindfulness, 9, 1390-1401. https://doi.org/10.1007/s12671-017-0879-7

Lo, H. H. M., Wong, J. Y. H., Wong, S. W. L., Wong, S. Y. S., Choi, C. W., Ho, R. T. H., Fong, R. W. T., \& Snel, E. (2019). Applying mindfulness to benefit economically disadvantaged families: A randomized controlled trial. Research on Social Work Practice. https://doi.org/10.1177/1049731518817142

Lo, H. H., Wong, S. W., Wong, J. Y., Yeung, J. W., Snel, E., \& Wong, S. Y. (2020). The effects of family-based mindfulness intervention on ADHD symptomology in young children and their parents: A randomized control trial. Journal of Attention Disorders. https:// doi.org/10.1177/10870547177433

Ni, M. Y., Yao, X., Leung, K. S. M., Yau, C., Leung, C. M. C., Lun, P., Flores, F. P., Chang, W. C., Cowling, B. J., \& Leung, G. M. (2020). Depression and post-traumatic stress during major social unrest in Hong Kong: A 10-year prospective cohort study. Lancet, 395(10220), 273-284.
Podsakoff, P. M., MacKenzie, S. B., Lee, J. Y., \& Podsakoff, N. P. (2003). Common method biases in behavioral research: A critical review of the literature and recommended remedies. Journal of Applied Psychology, 88(5), 879-903.

Shek, D. T. L., \& Sun, R. C. F. (2014). Parenting in Hong Kong: Traditional Chinese cultural roots and contemporary phenomena. In H. Selin (Ed.), Parenting across cultures: Childrearing, motherhood and fatherhood in non-Western cultures (pp. 25-38). Springer.

Singh, N. N., Singh, J., Singh, A. D. A., Singh, A. N. A., \& Winton, A. S. W. (2011). Meditation on the Soles of the Feet for anger management: A trainer's manual. Fernleaf.

Slone, M., \& Halls, D. (1999). The impact of political life events on children's psychological assessment. Anxiety, Stress \& Coping, 12(1), 1-21.

Smilkstein, G., Ashworth, C., \& Montano, D. (1982). Validity and reliability of the Family APGAR as a test of family function. Journal of Family Practice, 15, 303-311.

Soliz, J., \& Rittenour, C. E. (2012). Family as an intergroup arena. In $\mathrm{H}$. Giles (Ed.), The handbook of intergroup communication (pp. 331-343). Routledge.

Stiles, W. B. (1993). Quality control in qualitative research. Clinical Psychology Review, 13, 593-618.

Straus, M. A. (1979). Measuring intrafamily conflict and violence: The Conflict Tactics Scales. Journal of Marriage and the Family, 41, $75-88$.

Strauss, A., \& Corbin, J. (1998). Basics of qualitative research (2nd ed.). Sage.

Taylor, L. K., Merrilees, C. E., Gieke-Morey, M. C., Shirlow, P., \& Cummings, E. M. (2016). Trajectories of adolescent aggression and family cohesion: The potential to perpetuate or ameliorate political conflict. Journal of Clinical Child \& Adolescent Psychology, 45, 114-128.

Thomas, D. R. (2006). A general inductive approach for analyzing qualitative evaluation data. American Journal of Evaluation, 27, 237-246.

Townsend, D., Taylor, L. K., Merrilees, C. E., Furey, A., Goeke-Morey, M. C., Shirlow, P., \& Cummings, E. M. (2020). Youth in Northern Ireland: Linking violence exposure, emotional insecurity, and the political macrosystem. Monographs of the Society for Research in Child Development, 85(4), 7-123.

Vorhies, V., Guterman, N. B., \& Haj-Yahia, M. M. (2011). Community violence exposure and its effect. In N. R. Heller \& A. Gitterman (Eds.), Mental health and social problems: A social work perspective (pp. 225-256). Routledge.

Williams, M. (2020). Mindfulness in the time of coronavirus: New meditation tracks to help you cope. Available on http://franticwor ld.com/coronavirus/

Wong, K. T., Zheng, V., \& Wan, P. (2020). Local versus national identity in Hong Kong, 1998-2017. Journal of Contemporary Asia. https://doi.org/10.1080/00472336.2020

Publisher's Note Springer Nature remains neutral with regard to jurisdictional claims in published maps and institutional affiliations. 